OPEN ACCESS

Edited by:

D. Ceri Davies,

Imperial College London,

United Kingdom

Reviewed by:

Narasimham L. Parinandi,

The Ohio State University,

United States

Mayur Yergeri,

SVKM's Narsee Monjee Institute of

Management Studies, India

*Correspondence:

Sourav Bhattacharjee sourav.bhattacharjee@ucd.ie

${ }^{\dagger}$ These authors have contributed equally to this work

Specialty section:

This article was submitted to Translational Pharmacology,

a section of the journa

Frontiers in Pharmacology

Received: 03 December 2019

Accepted: 14 September 2020

Published: 02 October 2020

Citation:

Grzeszczuk Z, Rosillo A, Owens Ó and Bhattacharjee $S$ (2020) Atomic Force Microscopy (AFM) As a Surface Mapping Tool in Microorganisms Resistant Toward Antimicrobials: A Mini-Review.

Front. Pharmacol. 11:517165. doi: 10.3389/fphar.2020.517165

\section{Atomic Force Microscopy (AFM) As a Surface Mapping Tool in Microorganisms Resistant Toward Antimicrobials: A Mini-Review}

\author{
Zuzanna Grzeszczuk ${ }^{1 \dagger}$, Antoinette Rosillo ${ }^{1 \dagger}$, Óisín Owens ${ }^{1 \dagger}$ and Sourav Bhattacharjee ${ }^{2 *}$ \\ 1 School of Physics, Technological University Dublin, Dublin, Ireland, ${ }^{2}$ School of Veterinary Medicine, University College \\ Dublin (UCD), Dublin, Ireland
}

The worldwide emergence of antimicrobial resistance (AMR) in pathogenic microorganisms, including bacteria and viruses due to a plethora of reasons, such as genetic mutation and indiscriminate use of antimicrobials, is a major challenge faced by the healthcare sector today. One of the issues at hand is to effectively screen and isolate resistant strains from sensitive ones. Utilizing the distinct nanomechanical properties (e.g., elasticity, intracellular turgor pressure, and Young's modulus) of microbes can be an intriguing way to achieve this; while atomic force microscopy (AFM), with or without modification of the tips, presents an effective way to investigate such biophysical properties of microbial surfaces or an entire microbial cell. Additionally, advanced AFM instruments, apart from being compatible with aqueous environments-as often is the case for biological samples-can measure the adhesive forces acting between AFM tips/cantilevers (conjugated to bacterium/virion, substrates, and molecules) and target cells/surfaces to develop informative forcedistance curves. Moreover, such force spectroscopies provide an idea of the nature of intercellular interactions (e.g., receptor-ligand) or propensity of microbes to aggregate into densely packed layers, that is, the formation of biofilms - a property of resistant strains (e.g., Staphylococcus aureus, Pseudomonas aeruginosa). This mini-review will revisit the use of single-cell force spectroscopy (SCFS) and single-molecule force spectroscopy (SMFS) that are emerging as powerful additions to the arsenal of researchers in the struggle against resistant microbes, identify their strengths and weakness and, finally, prioritize some future directions for research.

\begin{abstract}
Keywords: antimicrobial resistance, multidrug resistance, atomic force microscopy (AFM), nanomechanics, nanoindentation, single-cell force spectroscopy (SCFS), single-molecule force spectroscopy (SMFS)
\end{abstract}

\section{INTRODUCTION}

The emergence of widespread antimicrobial resistance (AMR) exhibited now by many commonly encountered pathogens including bacteria (e.g., Gram-positive: Staphylococcus aureus, Streptococcus pyogenes, Mycobacterium tuberculosis, and Clostridium difficile; and Gram-negative: Escherichia coli, Klebsiella pneumoniae, Salmonella typhi, Pseudomonas aeruginosa, and Neisseria gonorroheae), 
viruses (e.g., hepatitis $\mathrm{B}$ and $\mathrm{C}$, herpes, and influenza), and fungi (e.g., Candida albicans, Aspergillus fumigatus, and Cryptococcus neoformans) against a range of popular antimicrobials, such as $\beta$ lactam antibiotics, macrolides, tetracyclines, aminoglycosides, fluoroquinolones, antihelminthics, and antifungals (Singer et al., 2016; Naylor et al., 2018; Hofer, 2019; Laws et al., 2019), in both human and veterinary medicine, such as the resistance noted against ivermectin in animal husbandry (O'Shaughnessy et al., 2019), is a major challenge today. Indiscriminate use of antibiotics due to their widespread availability and over-the-counter sales, often without prescription and in conjunction with poor sanitation, inadequate water purification, and wastewater management, as often occurs in developing countries, is posited to be a prime contributing factor to the surge of multidrug-resistant (MDR) strains, including methicillin-resistant Staphylococcus aureus (MRSA, Okwu et al., 2019) and vancomycin-resistant Enterococcus (VRE; Cetinkaya et al., 2000)—collectively termed as the superbugs (Davies and Davies, 2010; Khan and Khan, 2016). However, mutations within the genomes of microorganisms as an inherent trait to survive against antimicrobials are also a factor. Such AMR not only increases the mortality and morbidity from infectious diseases, but also increases drug toxicity in patients due to higher doses of antimicrobials required (Llor and Bjerrum, 2014). Additionally, AMR increases healthcare costs and creates a financial burden for resource-deprived countries. AMR is now declared a pandemic by the World Health Organization (WHO; MacIntyre and Bui, 2017) and one of the major healthcare challenges of this century, leaving the global population vulnerable to infectious diseases (Supplementary material).

A detailed discussion of the mechanisms of drug resistance falls beyond the scope of this review, but see Tenover, 2006; Munita and Arias, 2016; Peterson and Kaur, 2018. Most of the reported studies are based on bacterial resistance (Nikaido, 2009; Richardson, 2017), although accounts of viral (Irwin et al., 2016), fungal (Wiederhold, 2017), and parasitic resistance (Pramanik et al., 2019) are gradually being published. Scrutiny of the available literature reveals that resistant strains differ from sensitive ones in a few attributes, including biomechanical properties dictated by genetic makeup (Aguayo et al., 2015). It has been established that particularly in resistant bacterial strains, the cell walls are more rigid with reduced permeability and increased adhesiveness due to their altered composition (Harbottle et al., 2006; Aguayo et al., 2015), such as the cross-linked peptidoglycan and teichoic acid in bacteria (Muszanska et al., 2012); glycoproteins and phospholipids in virions (Ivanova et al., 2015); and chitins or glucans in fungi (Cowen et al., 2015). Such unusual and altered surface properties enable resistant strains to behave differently under biological and therapeutic circumstances. For example, the cell walls of resistant bacterial strains in general elicit greater stiffness and thickness (Tajkarimi et al., 2016) that deter the intracellular traffic of antimicrobial molecules, resulting in reduced drug efficacy. Similarly, due to increased adhesiveness, resistant bacteria are known to aggregate in densely packed layer(s) on biomaterials and produce biofilms due to both non-specific (e.g., acid-base and van der Waals) and specific (receptor-mediated binding to ligands) interactions (King and Korolik, 2017; Senneby et al., 2017; Carniello et al., 2018; Petridis et al., 2018), as reported for Staphylococcus aureus/epidermidis, Pseudomonas aeruginosa, Porphyromonas gingivalis, Treponema denticula, and Tanerella forsythia-the causative agents of infections refractory to antimicrobial therapy in cystic fibrosis (CF), endocarditis, osteomyelitis, sinusitis, otitis media, and nosocomial infections. An in-depth understanding of the cellular nanomechanical properties, including quantification of adhesive forces with nanoscale resolution and detection of molecular fingerprints and surface topography, have been hypothesized to be a strategy for identifying and then isolating resistant strains (Baptista et al., 2018). However, meeting such unique demands in biological samples high in aqueous content requires a sophisticated, versatile, robust, and highly sensitive analytic platform. Within the current inventory of analytic tools, atomic force microscopy (AFM) has emerged to satisfy most of the requirements described above, and therefore, much research into the biomechanics of microbes has relied on the use of AFM (Amro et al., 2000; Longo et al., 2013; Kelley, 2017; Kohler et al., 2019). This mini-review provides a brief understanding of the technique of AFM and investigates its possible applications.

\section{MODIFICATION OF AFM CANTILEVERS/ TIPS AND FORCE SPECTROSCOPY}

A detailed account of the principles of AFM is out of the scope of this article; however, relevant literature is available for readers (Dufrêne, 2003; Liu and Wang, 2010; Lilledahl and Stokke, 2015). Attaining nanoscale resolution in surface topography and compatibility with aqueous conditions underlie the utility of AFM in medical microbiology, particularly as emerging data continue to suggest that in comparison to drug sensitive strains, resistant strains possess distinct surface and nanomechanical properties, such as elasticity and intracellular turgor pressure (Dorobantu and Gray, 2010). Additionally, by taking the spring constant $(k)$ and vertical deflection $(d)$ of the cantilever into account, force $(F)$, such as the adhesive force (in $\mathrm{nN}$ or $\mathrm{pN}$ magnitude, Florin et al., 1994) acting between the sample and AFM tip (usually made of silicon nitride/ $\mathrm{Si}_{3} \mathrm{~N}_{4}$ ), can be quantified by Hooke's law: $\mathrm{F}=k d$ and thus, a forcedistance curve (Gavara, 2017; Figure 1A) can be developed revealing crucial information, such as quantification of (maximal) adhesive force and the nature of binding mediated by receptorligand interactions or formation of $\mathrm{H}$-bonds (Zlatanova et al., 2000; Newton et al., 2017; Figure 1B) while the tip is approaching or retreating from the sample. Moreover, the process of modifying AFM tips with substrates (e.g., bacteria), molecules (carbon nanotube, peptide, alkene, thiol, and silanol) or particles (nanoparticles, glass, or latex beads), has led to considerable advancement in recent years (Gan, 2007; Barattin and Voyer, 2008; Wilson and Macpherson, 2009), resulting in unprecedented resolution $(<1 \AA)$. With such advantages, research into single-cell force spectroscopy (SCFS) or single-molecule force spectroscopy (SMFS) has increased (Helenius et al., 2008; Neuman and Nagy, 2008; Hoffmann and Dougan, 2012; Taubenberger et al., 2013). Furthermore, AFM tips can be used to cause indentation on microbial surfaces (nanoindentation), to extract information about the mechanical properties and chemistry of surfaces, or microbial 


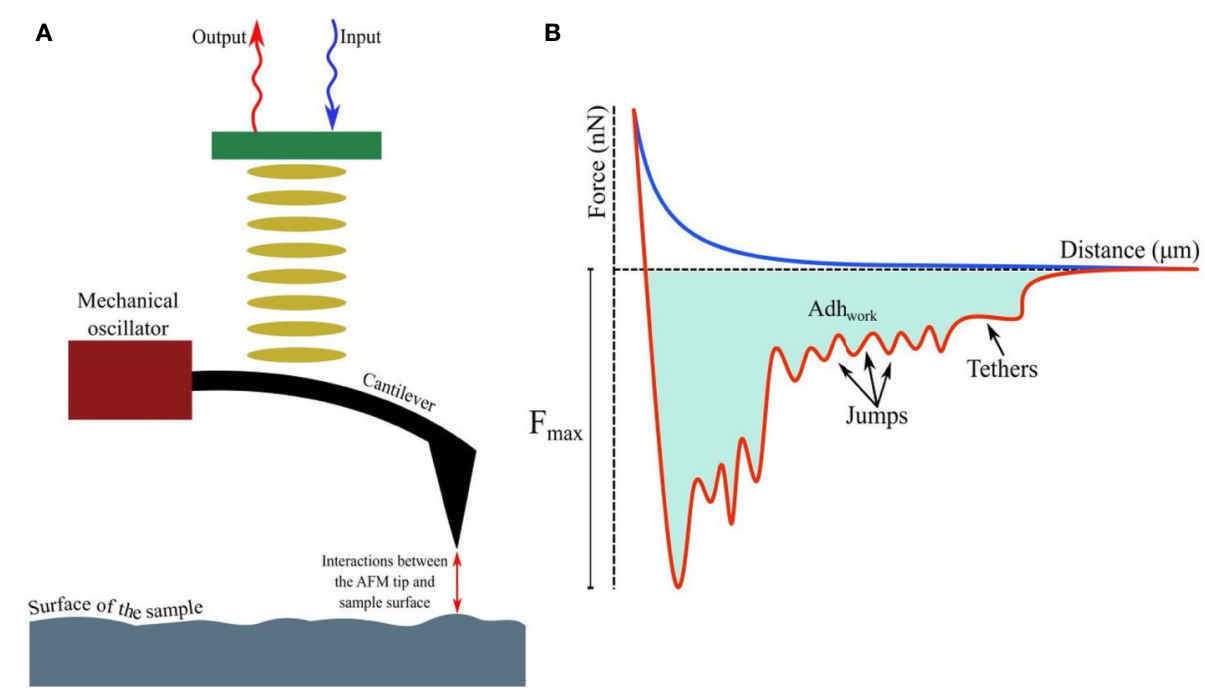

FIGURE 1 | (A) Fundamental principles of AFM showing interactions between the tip and probed surface. (B) The force-distance curve while a (modified) tip is brought in proximity to another cell, bacterium, or biomaterial. The curves, when the tip is approaching or retreating from the sample, are drawn in blue and red respectively. Receptor-ligand bonds, when strained due to increasing detachment force, are marked as 'jumps', while 'tethers' appear when detachment is complete at $F_{\text {max }}$. The shaded area denotes the total work done $\left(\mathrm{Adh}_{\text {work }}\right)$ against adhesive forces.

cells (Chen, 2014; Kontomaris et al., 2019). To facilitate immobilization of the tip or samples on surfaces (e.g., glass, mica, gold or silica) and minimize detachment (Suo et al., 2008; Allison et al., 2011) while conducting measurements, various adhesive materials have been used, such as poly-L-lysine, glutaraldehyde, polyethyleneimine, gelatin, and the biocompatible polymer polydopamine/poly-DOPA (Lee et al., 2007; Dreyer et al., 2012; Li et al., 2016; Li et al., 2017), in addition to simple surface adsorption.

\section{AFM-BASED MICROBIAL STUDIES}

The AFM cantilevers/tips have often been modified/tethered by attaching a bacterium with the help of adhesive materials (Figure 2). Cantilevers coated in poly-DOPA and attached to Escherichia coli bacterium have been used to probe biofilms of various microorganisms, including Massilia timonae, Pseudomonas aeruginosa, and Bacillus subtilis (Harimawan et al., 2011). However, the gradual heating of the cantilever upon being exposed to a laser beam affects cellular viability (Beaussart et al., 2013a), while the lack of uniformity during contact remains a challenge in SCFS. Hence, tip-less cantilevers attached to glass or latex beads $(300 \mathrm{~nm}-1 \mu \mathrm{m})$ are being increasingly used. Functionalized cantilevers have also been used to study the adhesive force between bacterial cells and hard surfaces, which increases over time of contact (usually $<60 \mathrm{~s}$ ), for example, between Staphylococcus epidermidis and fibrinogen-coated surfaces (Herman et al., 2013); Lactobacillus rhamnosus GG and mucin epithelial cells or hydrophobic surfaces (Sullan et al., 2014); Staphylococcus carnosus and hydrophilic/hydrophobic silicon wafers (Loskill et al., 2012); Escherichia coli and corundum $\left(\mathrm{Al}_{2} \mathrm{O}_{3}\right)$ or hematite $\left(\mathrm{Fe}_{2} \mathrm{O}_{3}\right)$ nanoparticles (Zhang et al., 2011); oral Streptococci and saliva-coated tooth enamel (Mei et al., 2009); oral microbiome and human saliva-coated bovine tooth enamel (Wessel et al., 2014); Staphylococcus aureus, Pseudomonas aeruginosa or Serratia marcescens and contact lenses coated in polypropylene and silver (Qu et al., 2013a), or brush-coated silica nanoparticles (Qu et al., 2013b).

AFM has been used to investigate the adhesion of bacteria to other microbes, cells, and molecules. This technique has found its niche, particularly in investigating the dynamics and nature of interactions between microbial surface receptors and ligands (Hinterdorfer and Dufrêne, 2006; Figure 2B). For example, gold AFM cantilevers coated in vancomycin ( $\sim 1 \mathrm{~nm}$ thickness) have been used to determine the surface density of D-Ala-D-Ala terminals of peptidoglycans expressed on Lactococcus lactis (Gilbert et al., 2007). Similarly, polyethyleneimine-coated cantilevers functionalized with Lactococcus lactis bacterium have been used to measure short (100-200 nm) and long $(600-800 \mathrm{~nm})$ distance interactions between the bacterium and porcine gastric mucin (Le et al., 2013). Such short and longdistance interactions were determined by elongated pili and mucin-binding proteins of the bacterium, respectively. In another study, cantilevers attached to a glass bead and coated in poly-DOPA were bioconjugated to Staphylococcus aureus, and SCFS was conducted (Beaussart et al., 2013b) to investigate its interactions with Candida albicans, a fungus often co-isolated from biofilms of Staphylococcus aureus (Ovchinnikova et al., 2012) in nosocomial infections (e.g., infected catheters/tubes), intra-abdominal sepsis and deep-seated abscess. The obtained data 4revealed that the peptides and lectin receptors on bacterial surface and Als-proteins plus $O$-mannosylated sites on fungi were major drivers of such interactions. Moreover, Staphylococcus aureus was noted to possess a higher affinity toward yeast tubes 

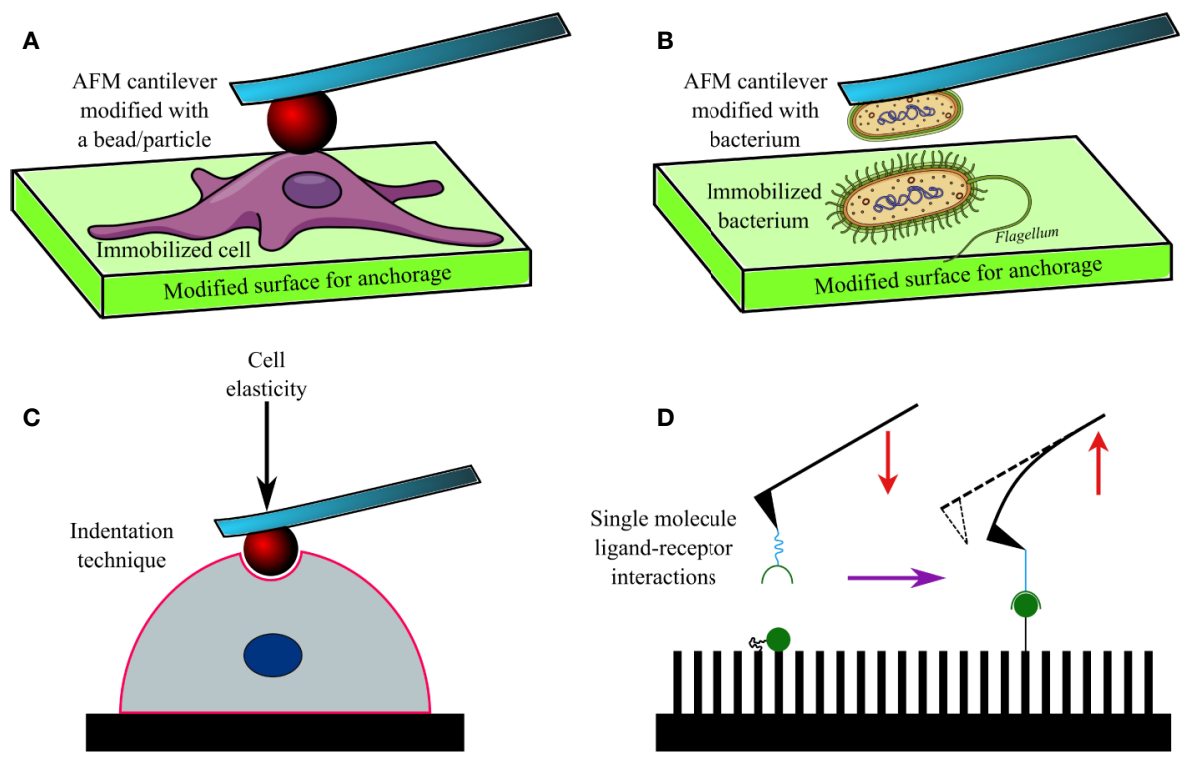

FIGURE 2 | A diagram showing an AFM cantilever modified with a bead (A), and bacterium (B) to perform indentation studies (C) on an immobilized cell or bacterium. Modified AFM tips are also used to investigate various ligand-receptor interactions (D) on functionalized surfaces.

than the yeast cells of Candida albicans. The role of LapA adhesin protein secreted by Pseudomonas fluorescens to enhance binding on hydrophobic surfaces was confirmed by assessing interactions between an AFM tip tethered with anti-hemagglutinin (HA) antibody and HA-tagged LapA deposited on hydrophobic alkanethiol-coated surfaces upon bacterial colonization (ElKirat-Chatel et al., 2014a; Figure 2D). In a further study the surface density of LapA adhesins on Pseudomonas fluorescens was shown to be $\sim 450$ sites $/ \mu \mathrm{m}^{2}$ and the adhesive force between surfaces and bacteria was shown to be increased in highly adhesive LapA+ mutant strains (El-Kirat-Chatel et al., 2014b).

Interestingly, AFM has been frequently used to determine hardness and elasticity of cell surfaces by inflicting nanoindentation with the tips, while Young's moduli of cells were calculated from cantilever deflection and its movement in the $z$-direction (Webb et al., 2011; Figure 2C). Nanoindentation studies can be performed under different conditions, including aqueous ones, and provide indepth information on nanomechanical properties of cells. Such a study conducted on Escherichia coli revealed heterogeneous stiffness of bacterial cells, with stiffer areas indicating proximity to intracellular organelles (Longo et al., 2012). Nanoindentation studies conducted on seven bacterial strains (Comamonas testosterone, Aeromonas punctata, Raoultella ornithinolytica, Bacillus cereus, Shewanella putrefaciens, Shewanella oneidensis, and Desulfovibrio vulgaris) established a correlation between their nanomechanical properties and the ability of the bacteria to aggregate (Wang et al., 2012). Nanomechanical investigations based on such indentation techniques have also helped to understand the effects of antibacterials such as ticarcillin and tobramycin (Formosa et al., 2012a), or novel antibiotics (Formosa et al., 2012b) on Pseudomonas aeruginosa; alginate oligosaccharide (OligoG) of low molecular weight on Acinetobacter baumannii and
Pseudomonas aeruginosa biofilms (Powell et al., 2013) and antimycobacterial drugs (ethambutol and isoniazid) on Mycobacterium sp. strain JLS (Wu and Zhou, 2009). By using tipless cantilevers functionalized with Staphylococcus aureus/ epidermidis, Streptococcus salivarius bacteria and a maximal loading force of $3 \mathrm{nN}$, it was discovered that Gram-positive bacteria demonstrated heterogeneous elasticity, comprising a rigid core and deformable cylindrical surface contact areas (Chen et al., 2012). Interestingly, Salmonella typhimurium regained its normal morphology and ability to divide after repeated punctures by AFM tips at multiple locations (Suo et al., 2009). Only a few researchers have reported success in imaging and mapping the distribution of proteins and protein complexes on bacterial cell walls of Halobacterium halobium (Worcester et al., 1988; Butt et al., 1990) and Deinococcus radiodurans (Karrasch et al., 1994) with lateral and vertical resolutions of $1 \mathrm{~nm}$ and $0.1 \mathrm{~nm}$ respectively. Furthermore, the effect of ambient factors, such as $\mathrm{pH}$, temperature, and ionic strength, on surface proteins of bacteria has been investigated by SCFS in Halobacterium salinarium (Oesterhelt et al., 2000). Similarly, the spatial distribution of polysaccharides on the surface of Lactobacillus rhamnosus GG, both wild type and CMPG5413 mutant with reduced production of polysaccharides, was probed with unmodified and modified AFM tips attached to lectin and concanavalin A (Francius et al., 2008). In another study, the stacks of lipopolysaccharide (LPS) molecules on Escherichia coli were imaged by AFM with a lateral and vertical resolution of $50 \AA$ and $5 \AA$, respectively (Amro et al., 2000). The role of LPS on adhesion of Escherichia coli was later also confirmed by force spectroscopy (Abu-Lail and Camesano, 2003). In a follow-up study on eight Escherichia coli strains, the length of LPSs on virulent strains carrying $\mathrm{O}$-antigens was reported to vary between $17 \pm 10 \mathrm{~nm}$ to $37 \pm 9 \mathrm{~nm}$; whereas they were much shorter $(3 \pm 2$ 
$\mathrm{nm}$ to $5 \pm 3 \mathrm{~nm}$ ) in strains lacking the O-antigen (Strauss et al., 2009). AFM has also been used to image bacterial appendages, such as pili and flagella, as well as their capsules (Tollersrud et al., 2001; Touhami et al., 2006; Dorobantu et al., 2008; Stukalov et al., 2008).

AFM has been used to measure intracellular bacterial turgor pressure that is important for maintaining cellular morphology and function (Beveridge, 1988; Doyle and Marquis, 1994; Walsby et al., 1995). It is usually higher in Gram-positive (20-50 atm) than in Gram-negative (3-5 atm) bacteria. Such AFM-based measurements of intra-bacterial turgor pressure have been conducted in Gram-negative Magnetospirillum gryphisw (85$150 \mathrm{kPa}$ in a buffer; Arnoldi et al., 2000), Gram-positive Enterococcus hirae (400-600 kPa in water) and Gram-negative Pseudomonas aeruginosa (10-20 $\mathrm{kPa}$ in a growth medium and $150-400 \mathrm{kPa}$ in water; Yao et al., 2002). Young's (elastic) moduli for various strains were measured by AFM-based indentation studies and were found to be lower $(1-10 \mathrm{kPa})$ than those of biomolecules such as proteins (0.5 GPa; Kuznetsova et al., 2007). Viable cells, however, demonstrated lower Young's moduli (3.0 \pm $0.6 \mathrm{MPa})$ than those with compromised cell walls $(6.1 \pm 1.5 \mathrm{MPa})$ or dead cells (Cerf et al., 2009). Such studies also revealed that in Gram-negative Shewanella putrefaciens, an increase in $\mathrm{pH}$ of the suspension medium from 4 to 10 resulted in a thicker cell wall with reduced stiffness (Gaboriaud et al., 2005).

\section{CHALLENGES}

It is difficult to model the interactive forces between a bacteriumprobe attached to a cantilever and cell probes like bacterium/cell/ ligands, because the current mainstay of modeling such interactions, the Derjaguin-Landau-Verwey-Overbeek (DLVO) theory, assumes that interacting surfaces are perfectly smooth and non-functionalized (Attard, 2003; Dorobantu et al., 2009). However, this is not the case in SCFS/SMFS studies, in which microbial surfaces are rough and often decorated with a diverse set of molecules, including biopolymers and macromolecules (Feick et al., 2004; Gotzinger and Peukert, 2004). A modified version of the DLVO model, such as the extended DLVO (XDLVO) that includes hydrophobic interactions or accounts for the polymers present on interacting surfaces, provides a more accurate model (Jucker et al., 1998), but further improvement is still necessary. Moreover, SCFS/ SMFS techniques are time-consuming, logistically demanding and labor-intensive, making their development into user-friendly pointof-care diagnostics unlikely in the forseeable future. Therefore, it is difficult to obtain statistically relevant clinical datasets, especially when performing comparative studies on multiple bacterial strains. The use of basic AFM requires training, while high-end utilization, for example cryogenic AFM, also requires considerable technical expertise and robust background knowledge, which may be an obstacle for interdisciplinary researchers from disparate disciplines.

\section{PERSPECTIVES}

Performing sophisticated SCFS/SMFS studies with modified AFM tips has opened novel avenues to investigate many unanswered questions regarding host-microbe or pathogensurface interactions. A better understanding of the intricacies of such interactions is crucial for developing high efficacy antimicrobial therapeutics. However, current technological challenges need to be addressed to convert currently available techniques into more user-friendly and flexible ones. In comparison to the molecular techniques for detecting AMR, such as the polymerase chain reaction and DNA-microarray technology (Fluit et al., 2001; Tan, 2003), AFM presents a simpler tool with lesser sample preparation requirements and greater cost-effectiveness. Additionally, techniques like SCFS/SMFS enable topographical analyses, including measurement of stiffness and elastic moduli, of various surfaces of interest, such as biofilms. Recent advances in AFM instrumentation have enabled studies on various organs of the human body, such as the brain (Viji Babu and Radmacher, 2019), lungs (Sicard et al., 2018) and liver (Saneyasu et al., 2016), including various physicochemical attributes, such as stiffness of the extracellular matrix (Jorba et al., 2017) and tissue architecture (Zapotoczny et al., 2017). In the future, it will be interesting to see whether AFM can differentiate between sensitive and resistant microorganisms based on measurements conducted on slices of infected tissues. However, tip modification techniques need further improvement to ensure higher resolution imaging and ultrasensitive measurements on biological samples and the ability to establish uniform contact areas with defined 2D and 3D geometry. Furthermore, systematic studies of resistant strains need to be performed, which will be a challenge given that such strains are rarely available for laboratory research and when available, pose a serious health-and-safety risk; working with such resistant microorganisms within non-containment AFM labs is realistically impracticable. Future research should be focused on these important areas to develop a growing range of applications for nanotech-tools in clinical microbiology, including investigation of AMR microbes.

\section{AUTHOR CONTRIBUTIONS}

$\mathrm{ZG}, \mathrm{AR}$, and OO conducted the literature survey and wrote the draft. SB supervised the entire project. All authors contributed to the article and approved the submitted version.

\section{FUNDING}

SB would like to thank UCD Research for funding.

\section{SUPPLEMENTARY MATERIAL}

The Supplementary Material for this article can be found online at: https://www.frontiersin.org/articles/10.3389/fphar.2020. 517165/full\#supplementary-material 


\section{REFERENCES}

Abu-Lail, N.II, and Camesano, T. A. (2003). Role of lipopolysaccharides in the adhesion, retention, and transport of Escherichia coli JM109. Environ. Sci. Technol. 37, 2173-2183. doi: 10.1021/es026159o

Aguayo, S., Donos, N., Spratt, D., and Bozec, L. (2015). Single-bacterium nanomechanics in biomedicine: unravelling the dynamics of bacterial cells. Nanotechnology 26, 062001. doi: 10.1088/0957-4484/26/6/062001

Allison, D. P., Sullivan, C. J., Mortensen, N. P., Retterer, S. T., and Doktycz, M. (2011). Bacterial immobilization for imaging by atomic force microscopy. J. Vis. Exp. 54, e2880. doi: $10.3791 / 2880$

Amro, N. A., Kotra, L. P., Wadu-Mesthrige, K., Bulychev, A., Mobashery, S., and Liu, G.-Y. (2000). High-resolution atomic force microscopy studies of the Escherichia coli outer membrane: structural basis for permeability. Langmuir 16, 2789-2796. doi: 10.1021/la991013x

Arnoldi, M., Fritz, M., Bauerlein, E., Radmacher, M., Sackmann, E., and Boulbitch, A. (2000). Bacterial turgor pressure can be measured by atomic force microscopy. Phys. Rev. E. 62, 1034-1044. doi: 10.1103/PhysRevE.62.1034

Attard, P. (2003). Nanobubbles and the hydrophobic attraction. Adv. Colloid, Interface Sci. 104, 75-91. doi: 10.1016/S0001-8686(03)00037-X

Baptista, P. V., McCusker, M. P., Carvalho, A., Ferreira, D. A., Mohan, N. M., Martins, M., et al. (2018). Nano-strategies to fight multidrug resistant bacteria-"a battle of the titans". Front. Microbiol. 9, 1441-1441. doi: 10.3389/fmicb.2018.01441

Barattin, R., and Voyer, N. (2008). Chemical modifications of AFM tips for the study of molecular recognition events. Chem. Commun. 2008, 1513-1532. doi: 10.1039/b614328h

Beaussart, A., El-Kirat-Chatel, S., Herman, P., Alsteens, D., Mahillon, J., Hols, P., et al. (2013a). Single-cell force spectroscopy of probiotic bacteria. Biophys. J. 104, 1886-1892. doi: 10.1016/j.bpj.2013.03.046

Beaussart, A., Herman, P., El-Kirat-Chatel, S., Lipke, P. N., Kucharíková, S., Van Dijck, P., et al. (2013b). Single-cell force spectroscopy of the medically important Staphylococcus epidermidis-Candida albicans interaction. Nanoscale 5, 10894-10900. doi: 10.1039/c3nr03272h

Beveridge, T. J. (1988). The bacterial surface - general-considerations towards design and function. Can. J. Microbiol. 34, 363-372. doi: 10.1139/m88-067

Butt, H. J., Downing, K. H., and Hansma, P. K. (1990). Imaging the membraneprotein bacteriorhodopsin with the atomic force microscope. Biophys. J. 58, 1473-1480. doi: 10.1016/S0006-3495(90)82492-9

Carniello, V., Peterson, B. W., van der Mei, H. C., and Busscher, H. J. (2018). Physico-chemistry from initial bacterial adhesion to surface-programmed biofilm growth. Adv. Colloid, Interface Sci. 261, 1-14. doi: 10.1016/j.cis.2018. 10.005

Cerf, A., Cau, J.-C., Vieu, C., and Dague, E. (2009). Nanomechanical properties of dead or alive single-patterned bacteria. Langmuir 25, 5731-5736. doi: 10.1021/ la9004642

Cetinkaya, Y., Falk, P., and Mayhall, C. G. (2000). Vancomycin-resistant Enterococci. Clin. Microbiol. Rev. 13, 686-707. doi: 10.1128/CMR.13.4.686

Chen, Y., Norde, W., van der Mei, H. C., and Busscher, H. J. (2012). Bacterial cell surface deformation under external loading. MBio 3, e00378-e00312. doi: 10.1128/mBio.00378-12

Chen, J. (2014). Nanobiomechanics of living cells: a review. Interface Focus 4, 20130055. doi: 10.1098/rsfs.2013.0055

Cowen, L. E., Sanglard, D., Howard, S. J., Rogers, P. D., and Perlin, D. S. (2015). Mechanisms of antifungal drug resistance. Cold Spring Harb. Perspect. Med. 5, a019752. doi: 10.1101/cshperspect.a019752

Davies, J., and Davies, D. (2010). Origins and evolution of antibiotic resistance. Microbiol. Mol. Biol. Rev. 74, 417-433. doi: 10.1128/MMBR.00016-10

Dorobantu, L. S., and Gray, M. R. (2010). Application of atomic force microscopy in bacterial research. Scanning 32, 74-96. doi: 10.1002/sca.20177

Dorobantu, L. S., Bhattacharjee, S., Foght, J. M., and Gray, M. R. (2008). Atomic force microscopy measurement of heterogeneity in bacterial surface hydrophobicity. Langmuir 24, 4944-4951. doi: 10.1021/la7035295

Dorobantu, L. S., Bhattacharjee, S., Foght, J. M., and Gray, M. R. (2009). Analysis of force interactions between AFM tips and hydrophobic bacteria using DLVO theory. Langmuir 25, 6968-6976. doi: 10.1021/la9001237

Doyle, R. J., and Marquis, R. E. (1994). Elastic, flexible peptidoglycan and bacterial cell wall properties. Trends Microbiol. 2, 57-60. doi: 10.1016/0966-842X(94) 90127-9
Dreyer, D. R., Miller, D. J., Freeman, B. D., Paul, D. R., and Bielawski, C. W. (2012). Elucidating the structure of poly(dopamine). Langmuir 28, 6428-6435. doi: 10.1021/la204831b

Dufrêne, Y. F. (2003). Recent progress in the application of atomic force microscopy imaging and force spectroscopy to microbiology. Curr. Opin. Microbiol. 6, 317-323. doi: 10.1016/S1369-5274(03)00058-4

El-Kirat-Chatel, S., Boyd, C. D., O'Toole, G. A., and Dufrêne, Y. F. (2014a). Singlemolecule analysis of Pseudomonas fluorescens footprints. ACS Nano 8, 16901698. doi: $10.1021 / \mathrm{nn} 4060489$

El-Kirat-Chatel, S., Beaussart, A., Boyd, C. D., O’Toole, G. A., and Dufrêne, Y. F. (2014b). Single-cell and single-molecule analysis deciphers the localization, adhesion, and mechanics of the biofilm adhesin LapA. ACS Chem. Biol. 9, 485494. doi: $10.1021 / \mathrm{cb} 400794 \mathrm{e}$

Feick, J. D., Chukwumah, N., Noel, A. E., and Velegol, D. (2004). Altering surface charge nonuniformity on individual colloidal particles. Langmuir 20, 30903095. doi: $10.1021 / \mathrm{la} 0355545$

Florin, E. L., Moy, V. T., and Gaub, H. E. (1994). Adhesion forces between individual ligand-receptor pairs. Science 264, 415-417. doi: 10.1126 science. 8153628

Fluit, A. C., Visser, M. R., and Schmitz, F. J. (2001). Molecular detection of antimicrobial resistance. Clin. Microbiol. Rev. 14, 836-871. doi: 10.1128/ CMR.14.4.836-871.2001

Formosa, C., Grare, M., Duval, R. E., and Dague, E. (2012a). Nanoscale effects of antibiotics on $P$. aeruginosa. Nanomed.: NBM 8, 12-16. doi: 10.1016/ j.nano.2011.09.009

Formosa, C., Grare, M., Jauvert, E., Coutable, A., Regnouf-de-Vains, J. B., Mourer, M., et al. (2012b). Nanoscale analysis of the effects of antibiotics and CX1 on a Pseudomonas aeruginosa multidrug-resistant strain. Sci. Rep. 2, 575. doi: 10.1038/ srep00575

Francius, G., Lebeer, S., Alsteens, D., Wildling, L., Gruber, H. J., Hols, P., et al. (2008). Detection, localization, and conformational analysis of single polysaccharide molecules on live bacteria. ACS Nano 2, 1921-1929. doi: $10.1021 / \mathrm{nn} 800341 \mathrm{~b}$

Gaboriaud, F., Bailet, S., Dague, E., and Jorand, F. (2005). Surface structure and nanomechanical properties of Shewanella putrefaciens bacteria at two $\mathrm{pH}$ values (4 and 10) determined by atomic force microscopy. J. Bacteriol. 187, 3864-3868. doi: 10.1128/JB.187.11.3864-3868.2005

Gan, Y. (2007). Invited review article: A review of techniques for attaching microand nanoparticles to a probe's tip for surface force and near-field optical measurements. Rev. Sci. Instrum. 78, 081101. doi: 10.1063/1.2754076

Gavara, N. (2017). A beginner's guide to atomic force microscopy probing for cell mechanics. Microsc. Res. Tech. 80, 75-84. doi: 10.1002/jemt.22776

Gilbert, Y., Deghorain, M., Wang, L., Xu, B., Pollheimer, P. D., Gruber, H. J., et al. (2007). Single-molecule force spectroscopy and imaging of the vancomycin/DAla-D-Ala interaction. Nano Lett. 7, 796-801. doi: 10.1021/nl0700853

Götzinger, M., and Peukert, W. (2004). Particle adhesion force distributions on rough surfaces. Langmuir 20, 5298-5303. doi: 10.1021/la049914f

Harbottle, H., Thakur, S., Zhao, S., and White, D. G. (2006). Genetics of antimicrobial resistance. Anim. Biotechnol. 17, 111-124. doi: 10.1080/ 10495390600957092

Harimawan, A., Rajasekar, A., and Ting, Y.-P. (2011). Bacteria attachment to surfaces - AFM force spectroscopy and physicochemical analyses. J. Colloid, Interface Sci. 364, 213-218. doi: 10.1016/j.jcis.2011.08.021

Helenius, J., Heisenberg, C.-P., Gaub, H. E., and Muller, D. J. (2008). Single-cell force spectroscopy. J. Cell Sci. 121, 1785-1791. doi: 10.1242/jcs.030999

Herman, P., El-Kirat-Chatel, S., Beaussart, A., Geoghegan, J. A., Vanzieleghem, T., Foster, T. J., et al. (2013). Forces driving the attachment of Staphylococcus epidermidis to fibrinogen-coated surfaces. Langmuir 29, 13018-13022. doi: $10.1021 / \mathrm{la} 4029172$

Hinterdorfer, P., and Dufrêne, Y. F. (2006). Detection and localization of single molecular recognition events using atomic force microscopy. Nat. Methods 3 , 347-355. doi: 10.1038/nmeth871

Hofer, U. (2019). The cost of antimicrobial resistance. Nat. Rev. Microbiol. 17, 3-3. doi: 10.1038/s41579-018-0125-x

Hoffmann, T., and Dougan, L. (2012). Single molecule force spectroscopy using polyproteins. Chem. Soc Rev. 41, 4781-4796. doi: 10.1039/c2cs35033e

Irwin, K. K., Renzette, N., Kowalik, T. F., and Jensen, J. D. (2016). Antiviral drug resistance as an adaptive process. Virus Evol. 2, 1-10. doi: 10.1093/ve/vew014 
Ivanova, P. T., Myers, D. S., Milne, S. B., McClaren, J. L., Thomas, P. G., and Brown, H. A. (2015). Lipid composition of viral envelope of three strains of influenza virus - not all viruses are created equal. ACS Infect. Dis. 1, 399-452. doi: 10.1021/acsinfecdis.5b00040

Jorba, I., Uriarte, J. J., Campillo, N., Farré, R., and Navajas, D. (2017). Probing micromechanical properties of the extracellular matrix of soft tissues by atomic force microscopy. J. Cell. Physiol. 232, 19-26. doi: 10.1002/jcp.25420

Jucker, B. A., Zehnder, A. J. B., and Harms, H. (1998). Quantification of polymer interactions in bacterial adhesion. Environ. Sci. Technol. 32, 2909-2915. doi: $10.1021 /$ es 980211 s

Karrasch, S., Hegerl, R., Hoh, J. H., Baumeister, W., and Engel, A. (1994). Atomicforce microscopy produces faithful high-resolution images of protein surfaces in an aqueous environment. Proc. Natl. Acad. Sci. U.S.A. 91, 836-838. doi: 10.1073/pnas.91.3.836

Kelley, S. O. (2017). New technologies for rapid bacterial identification and antibiotic resistance profiling. SLAS Technol. 22, 113-121. doi: 10.1177/ 2211068216680207

Khan, S. N., and Khan, A. U. (2016). Breaking the spell: combating multidrug resistant 'superbugs'. Front. Microbiol. 7, 174. doi: 10.3389/fmicb.2016.00174

King, R. M., and Korolik, V. (2017). Characterization of ligand-receptor interactions: chemotaxis, biofilm, cell culture assays, and animal model methodologies. Methods Mol. Biol. 1512, 149-161. doi: 10.1007/978-1-49396536-6_13

Kohler, A. C., Venturelli, L., Longo, G., Dietler, G., and Kasas, S. (2019). Nanomotion detection based on atomic force microscopy cantilevers. Cell Surf. 5, 100021. doi: 10.1016/j.tcsw.2019.100021

Kontomaris, S. V., Stylianou, A., Nikita, K. S., and Malamou, A. (2019). Determination of the linear elastic regime in AFM nanoindentation experiments on cells. Mater. Res. Express 6, 115410. doi: 10.1088/2053-1591/ab4f42

Kuznetsova, T. G., Starodubtseva, M. N., Yegorenkov, N.II, Chizhik, S. A., and Zhdanov, R.II (2007). Atomic force microscopy probing of cell elasticity. Micron 38, 824-833. doi: 10.1016/j.micron.2007.06.011

Laws, M., Shaaban, A., and Rahman, K. M. (2019). Antibiotic resistance breakers: current approaches and future directions. FEMS Microbiol. Rev. 43, 490-516. doi: 10.1093/femsre/fuz014

Le, D. T. L., Tran, T.-L., Duviau, M.-P., Meyrand, M., Guérardel, Y., Castelain, M., et al. (2013). Unraveling the role of surface mucus-binding protein and pili in muco-adhesion of Lactococcus lactis. PloS One 8, e79850. doi: 10.1371/ journal.pone.0079850

Lee, H., Dellatore, S. M., Miller, W. M., and Messersmith, P. B. (2007). Musselinspired surface chemistry for multifunctional coatings. Science 318, 426-430. doi: $10.1126 /$ science.1147241

Li, Q., Zhang, T., Pan, Y., Ciacchi, L. C., Xu, B., and Wei, G. (2016). AFM-based force spectroscopy for bioimaging and biosensing. RSC Adv. 6, 12893-12912. doi: 10.1039/C5RA22841G

Li, M., Dang, D., Xi, N., Wang, Y., and Liu, L. (2017). Nanoscale imaging and force probing of biomolecular systems using atomic force microscopy: from single molecules to living cells. Nanoscale 9, 17643-17666. doi: 10.1039/ C7NR07023C

Lilledahl, M. B., and Stokke, B. T. (2015). Novel imaging technologies for characterization of microbial extracellular polysaccharides. Front. Microbiol. 6, 525. doi: 10.3389/fmicb.2015.00525

Liu, S., and Wang, Y. (2010). Application of AFM in microbiology: a review. Scanning 32, 61-73. doi: 10.1002/sca.20173

Llor, C., and Bjerrum, L. (2014). Antimicrobial resistance: risk associated with antibiotic overuse and initiatives to reduce the problem. Ther. Adv. Drug Saf. 5, 229-241. doi: 10.1177/2042098614554919

Longo, G., Rio, L. M., Roduit, C., Trampuz, A., Bizzini, A., Dietler, G., et al. (2012). Force volume and stiffness tomography investigation on the dynamics of stiff material under bacterial membranes. J. Mol. Recognit. 25, 278-284. doi: 10.1002/jmr.2171

Longo, G., Alonso-Sarduy, L., Rio, L. M., Bizzini, A., Trampuz, A., Notz, J., et al. (2013). Rapid detection of bacterial resistance to antibiotics using AFM cantilevers as nanomechanical sensors. Nat. Nanotechnol. 8, 522-526. doi: 10.1038/nnano.2013.120

Loskill, P., Hähl, H., Thewes, N., Kreis, C. T., Bischoff, M., Herrmann, M., et al. (2012). Influence of the subsurface composition of a material on the adhesion of Staphylococci. Langmuir 28, 7242-7248. doi: 10.1021/la3004323
MacIntyre, C. R., and Bui, C. M. (2017). Pandemics, public health emergencies and antimicrobial resistance - putting the threat in an epidemiologic and risk analysis context. Arch. Public Health 75, 54-54. doi: 10.1186/s13690-017-0223-7

Mei, L., Ren, Y., Busscher, H. J., Chen, Y., and van der Mei, H. C. (2009). Poisson analysis of streptococcal bond-strengthening on saliva-coated enamel. J. Dent. Res. 88, 841-845. doi: 10.1177/0022034509342523

Munita, J. M., and Arias, C. A. (2016). Mechanisms of antibiotic resistance. Microbiol. Spectr. 4, 1-24. doi: 10.1128/microbiolspec.VMBF-0016-2015

Muszanska, A. K., Nejadnik, M. R., Chen, Y., van den Heuvel, E. R., Busscher, H. J., van der MEI, H. C., et al. (2012). Bacterial adhesion forces with substratum surfaces and the susceptibility of biofilms to antibiotics. Antimicrob. Agents Chemother. 56, 4961-4964. doi: 10.1128/AAC.00431-12

Naylor, N. R., Atun, R., Zhu, N., Kulasabanathan, K., Silva, S., Chatterjee, A., et al. (2018). Estimating the burden of antimicrobial resistance: a systematic literature review. Antimicrob. Resist. Infect. Control 7, 58. doi: 10.1186/s13756-018-0336-y

Neuman, K. C., and Nagy, A. (2008). Single-molecule force spectroscopy: optical tweezers, magnetic tweezers and atomic force microscopy. Nat. Methods 5, 491-505. doi: 10.1038/nmeth.1218

Newton, R., Delguste, M., Koehler, M., Dumitru, A. C., Laskowski, P. R., Müller, D. J., et al. (2017). Combining confocal and atomic force microscopy to quantify single-virus binding to mammalian cell surfaces. Nat. Protoc. 12, 2275-2292. doi: 10.1038/nprot.2017.112

Nikaido, H. (2009). Multidrug resistance in bacteria. Annu. Rev. Biochem. 78, 119 146. doi: 10.1146/annurev.biochem.78.082907.145923

Oesterhelt, F., Oesterhelt, D., Pfeiffer, M., Engel, A., Gaub, H. E., and Muller, D. J. (2000). Unfolding pathways of individual bacteriorhodopsins. Science 288, 143-146. doi: 10.1126/science.288.5463.143

Okwu, M. U., Olley, M., Akpoka, A. O., and Izevbuwa, O. E. (2019). Methicillinresistant Staphylococcus aureus (MRSA) and anti-MRSA activities of extracts of some medicinal plants: a brief review. AIMS Microbiol. 5, 117-137. doi: 10.3934/microbiol.2019.2.117

O’Shaughnessy, J., Drought, Y., Lynch, J., Denny, M., Hurley, C., Byrne, W., et al. (2019). Ivermectin treatment failure on four Irish dairy farms. Irish Vet. J. 72, 4. doi: 10.1186/s13620-019-0142-8

Ovchinnikova, E. S., Krom, B. P., Busscher, H. J., and van der Mei, H. C. (2012). Evaluation of adhesion forces of Staphylococcus aureus along the length of Candida albicans hyphae. BMC Microbiol. 12, 281. doi: 10.1186/1471-2180-12-281

Peterson, E., and Kaur, P. (2018). Antibiotic resistance mechanisms in bacteria: relationships between resistance determinants of antibiotic producers, environmental bacteria, and clinical pathogens. Front. Microbiol. 9, 2928. doi: $10.3389 /$ fmicb.2018.02928

Petridis, X., van der Sluis, L. W. M., Dijkstra, R. J. B., Brinker, M. G. L., van der Mei, H. C., and Harmsen, M. C. (2018). Secreted products of oral bacteria and biofilms impede mineralization of apical papilla stem cells in TLR-, species-, and culture-dependent fashion. Sci. Rep. 8, 12529. doi: 10.1038/s41598-01830658-5

Powell, L. C., Sowedan, A., Khan, S., Wright, C. J., Hawkins, K., Onsoyen, E., et al. (2013). The effect of alginate oligosaccharides on the mechanical properties of Gram-negative biofilms. Biofouling 29, 413-421. doi: 10.1080/08927014. 2013.777954

Pramanik, P. K., Alam, M. N., Roy Chowdhury, D., and Chakraborti, T. (2019). Drug resistance in protozoan parasites: an incessant wrestle for survival. J. Glob. Antimicrob. Resist. 18, 1-11. doi: 10.1016/j.jgar.2019.01.023

Qu, W., Busscher, H. J., van der Mei, H. C., and Hooymans, J. M. M. (2013a). Bacterial adhesion forces to Ag-impregnated contact lens cases and transmission to contact lenses. Cornea 32, 326-331. doi: 10.1097/ICO.0b013e31825837ea

Qu, W., Hooymans, J. M. M., Qiu, J., de-Bont, N., Gelling, O.-J., van der Mei, H. C., et al. (2013b). Nonadhesive, silica nanoparticles-based brush-coated contact lens cases-compromising between ease of cleaning and microbial transmission to contact lenses. J. Biomed. Mater. Res. B. 101B, 640-647. doi: 10.1002/jbm.b.32866

Richardson, L. A. (2017). Understanding and overcoming antibiotic resistance. PloS Biol. 15, e2003775. doi: 10.1371/journal.pbio.2003775

Saneyasu, T., Akhtar, R., and Sakai, T. (2016). Molecular cues guiding matrix stiffness in liver fibrosis. BioMed. Res. Int. 2016, 2646212. doi: 10.1155/2016/ 2646212

Senneby, A., Davies, J. R., Svensäter, G., and Neilands, J. (2017). Acid tolerance properties of dental biofilms in vivo. BMC Microbiol. 17, 165. doi: 10.1186/ s12866-017-1074-7 
Sicard, D., Haak, A. J., Choi, K. M., Craig, A. R., Fredenburgh, L. E., and Tschumperlin, D. J. (2018). Aging and anatomical variations in lung tissue stiffness. Am. J. Physiol. Lung Cell. Mol. Physiol. 314, L946-L955. doi: 10.1152/ ajplung.00415.2017

Singer, A. C., Shaw, H., Rhodes, V., and Hart, A. (2016). Review of antimicrobial resistance in the environment and its relevance to environmental regulators. Front. Microbiol. 7, 1728. doi: 10.3389/fmicb.2016.01728

Strauss, J., Burnham, N. A., and Camesano, T. A. (2009). Atomic force microscopy study of the role of LPS O-antigen on adhesion of E. coli. J. Mol. Recognit. 22, 347-355. doi: 10.1002/jmr.955

Stukalov, O., Korenevsky, A., Beveridge, T. J., and Dutcher, J. R. (2008). Use of atomic force microscopy and transmission electron microscopy for correlative studies of bacterial capsules. Appl. Environ. Microbiol. 74, 5457. doi: 10.1128/AEM.02075-07

Sullan, R. M. A., Beaussart, A., Tripathi, P., Derclaye, S., El-Kirat-Chatel, S., LI, J. K., et al. (2014). Single-cell force spectroscopy of pili-mediated adhesion. Nanoscale 6, 1134-1143. doi: 10.1039/C3NR05462D

Suo, Z., Avci, R., Yang, X., and Pascual, D. W. (2008). Efficient immobilization and patterning of live bacterial cells. Langmuir 24, 4161-4167. doi: 10.1021/ la7038653

Suo, Z., Avci, R., Deliorman, M., Yang, X., and Pascual, D. W. (2009). Bacteria survive multiple puncturings of their cell walls. Langmuir 25, 4588-4594. doi: $10.1021 /$ la8033319

Tajkarimi, M., Harrison, S. H., Hung, A. M., and Graves, J. L.Jr. (2016). Mechanobiology of antimicrobial resistant Escherichia coli and Listeria innocua. PloS One 11, e0149769. doi: 10.1371/journal.pone.0149769

Tan, T. Y. (2003). Use of molecular techniques for the detection of antibiotic resistance in bacteria. Exp. Rev. Mol. Diagn. 3, 93-103. doi: 10.1586/14737159.3.1.93

Taubenberger, A. V., Hutmacher, D. W., and Muller, D. J. (2013). Single-cell force spectroscopy, an emerging tool to quantify cell adhesion to biomaterials. Tissue Eng. Part B. Rev. 20, 40-55. doi: 10.1089/ten.teb.2013.0125

Tenover, F. C. (2006). Mechanisms of antimicrobial resistance in bacteria. Am. J. Infect. Control 34, S3-S10. doi: 10.1016/j.amjmed.2006.03.011

Tollersrud, T., Berge, T., Andersen, S. R., and Lund, A. (2001). Imaging the surface of Staphylococcus aureus by atomic force microscopy. APMIS 109, 541-545. doi: 10.1111/j.1600-0463.2001.apm090708.x

Touhami, A., Jericho, M. H., Boyd, J. M., and Beveridge, T. J. (2006). Nanoscale characterization and determination of adhesion forces of Pseudomonas aeruginosa pili by using atomic force microscopy. J. Bacteriol. 188, 370. doi: 10.1128/JB.188.2.370-377.2006

Viji Babu, P. K., and Radmacher, M. (2019). Mechanics of brain tissues studied by atomic force microscopy: a perspective. Front. Neurosci. 13, 600. doi: 10.3389/ fnins.2019.00600

Walsby, A. E., Hayes, P. K., and Boje, R. (1995). The gas vesicles, buoyancy and vertical distribution of cyanobacteria in the Baltic Sea. Eur. J. Phycol. 30, 87-94. doi: 10.1080/09670269500650851

Wang, X., LI, Y. Y., Onnis-Hayden, A., Gao, C., GU, A. Z., and Wan, K. T. (2012). Correlation of macroscopic aggregation behavior and microscopic adhesion properties of bacteria strains using a dimensionless Tabor's parameter. J. Colloid, Interface Sci. 374, 70-76. doi: 10.1016/j.jcis.2012.01.032

Webb, H. K., Truong, V. K., Hasan, J., Crawford, R. J., and Ivanova, E. P. (2011). Physico-mechanical characterisation of cells using atomic force microscopy current research and methodologies. J. Microbiol. Methods 86, 131-139. doi: 10.1016/j.mimet.2011.05.021

Wessel, S. W., Chen, Y., Maitra, A., van den Heuvel, E. R., Slomp, A. M., Busscher, H. J., et al. (2014). Adhesion forces and composition of planktonic and adhering oral microbiomes. J. Dent. Res. 93, 84-88. doi: 10.1177/ 0022034513511822

Wiederhold, N. P. (2017). Antifungal resistance: current trends and future strategies to combat. Infect. Drug Resist. 10, 249-259. doi: 10.2147/ IDR.S124918

Wilson, N. R., and Macpherson, J. V. (2009). Carbon nanotube tips for atomic force microscopy. Nat. Nanotechnol. 4, 483-491. doi: 10.1038/nnano.2009.154

Worcester, D. L., Miller, R. G., and Bryant, P. J. (1988). Atomic force microscopy of purple membranes. J. Microsc. 152, 817-821. doi: 10.1111/j.13652818.1988.tb01454.x

Wu, Y., and Zhou, A. (2009). In situ, real-time tracking of cell wall topography and nanomechanics of antimycobacterial drugs treated Mycobacterium JLS using atomic force microscopy. Chem. Commun. 2009, 7021-7023. doi: 10.1039/ b914605a

Yao, X., Walter, J., Burke, S., Stewart, S., Jericho, M. H., Pink, D., et al. (2002). Atomic force microscopy and theoretical considerations of surface properties and turgor pressures of bacteria. Colloids Surf. B. Biointerf. 23, 213-230. doi: 10.1016/S0927-7765(01)00249-1

Zapotoczny, B., Szafranska, K., Owczarczyk, K., Kus, E., Chlopicki, S., and Szymonski, M. (2017). Atomic force microscopy reveals the dynamic morphology of fenestrations in live liver sinusoidal endothelial cells. Sci. Rep. 7, 7994. doi: 10.1038/s41598-017-08555-0

Zhang, W., Stack, A. G., and Chen, Y. (2011). Interaction force measurement between $E$. coli cells and nanoparticles immobilized surfaces by using AFM. Colloids Surf. B. Biointerf. 82, 316-324. doi: 10.1016/j.colsurfb.2010.09.003

Zlatanova, J., Lindsay, S. M., and Leuba, S. H. (2000). Single molecule force spectroscopy in biology using the atomic force microscope. Prog. Biophys. Mol. Biol. 74, 37-61. doi: 10.1016/S0079-6107(00)00014-6

Conflict of Interest: The authors declare that the research was conducted in the absence of any commercial or financial relationships that could be construed as a potential conflict of interest.

Copyright (c) 2020 Grzeszczuk, Rosillo, Owens and Bhattacharjee. This is an open-access article distributed under the terms of the Creative Commons Attribution License (CC BY). The use, distribution or reproduction in other forums is permitted, provided the original author(s) and the copyright owner(s) are credited and that the original publication in this journal is cited, in accordance with accepted academic practice. No use, distribution or reproduction is permitted which does not comply with these terms. 